\title{
LA UTILIZACIÓN DE LAS FUNCIONES POÉTICAS EN LA GALATEA
}

La Galatea, a pesar de su carácter primerizo y de los diversos méritos que la crítica le ha atribuido, es el resultado de la cuidadosa labor creativa de Cervantes que, conscientemente, parte de un género de moda en su tiempo para llevarlo a sus extremas posibilidades de experimentación ${ }^{1}$. En el prólogo, al referirse a su obra como égloga, además de inserirse en una tradición que de Teócrito y Virgilio llega a la moderna novela de pastores, se sitúa en un

1 Como se sabe el interes de la crítica para con la novela pastoril y la reevaluación de La Galatea de Cervantes remontan a tiempos recientes pero ya se puede contar con numerosos trabajos. Para un estado de la cuestión remito al artículo de Juan Bautista Avalle-Arce, \& La Galatea de Cervantes cuatrocientos ańos después», en La Galatea de Cervantes cuatrocientos años después (Cenvantes y lo pastoril). Newark, Delaware: Juan de la Cuesta, 1985, 1-6. Como bibliografía general es preciso citar Cervantes and the Pastoral. Cleveland, Cleveland State University, 1986; Pilar Fernandez-Canadas de Greenwood, Pastoral Poetics: the Uses of Conventions in Renaissance Pastoral Romances, Arcadia, La Diana, La Galatea L'Astrée. Madrid, Ediciones José Porrúa Turanzas, 1983; Alban Forcione, «Cervantes en busca de una pastoral auténticax, Nueva Revista de Filologia Hispanica, 36, 1988, 1011-43 y *La Galatea» de Johoutn Casalduero, en Suma Cervantina, London, Tamesis, 1973, 27-46. Siguen manteniendo su validez los dos estudios de Francisco Lópzz EsTruDA, La «Galatea* de Cervantes. Estudio Critico. Tenerife, Universidad de La Laguna, 1948 y Los libros de pastores en la literatura española. La órbita previa. Madrid, Gredos, 1974 y el de Juan Bautista Avalle-ArCe, La novela pastoril española, reeditado por la Revista de Occidente, Madrid, 1959. LOPEZ EsTrudA ha publicado también el artículo «La literatura pastoril y Cervantes: el caso de La Galatea», en Actas del I Coloquio Intemecional de la Asociación de Cervantistas. Barcelona, Ed. Anthropos, 1990, 159-74. Finalmente, recordemos EDWARD C. RILEY, Teorta de la novela en Cervantes. Madrid, Taurus, 1966 y el ya clásico AMrrico CASTRO, El pensamiento de Cervantes. Barcelona, Noguer, 1980. 
amplio campo literario que deja espacio a la creatividad del escritor, aun permaneciendo dentro de las convenciones del género ${ }^{2}$.

La mezcla de prosa y verso que, a partir de la Arcadia de Sannazaro, se impone como una de las características más peculiares de la novela pastoril, es uno de los aspectos más trabajados por Cervantes que evidencia su voluntad de experimentar con la técnica narrativa. Ya se ha superado, por lo menos en parte, el antiguo prejuicio de la crítica para con la poesía del autor del Quijote ${ }^{3}$. Los

2 Comenta FERNANDEZ-CANAdA en el ensayo citado: «Along with the romance, the Eclogue is the most widely known form derived from the early idylls, which in turn proved to be adaptable to all sorts of literary expressions from the sentimental to the political, from the lyric to the dramatic, from the panegyric to the parodic. Because of their conciseness and flexible character, they provide a special kind of unity where full vignettes, themes and episodes can be developed. (41-42). El hecho de que la novela pastoril quedara al margen de las poetitcas contemporáneas, que no la incluian dentro de la rosa de los géneros principales y que no sabían exactamente cómo clasificarla, dejaba efectivamente a los autores un ancho margen de libertad creadora del que Cervantes se aprovechó ampliamente. Alberto Porouzras-Mayo en aCervantes y la teoria poética», Actas del II Coloquio Intemacional de la Asociación de Cervantistas (Barcelona, Ed. Anthropos, 1991) comenta: «Cervantes conoce las "reglas" y las transita, más o menos, para, al alimón con el lector cómplice, llegar a la flamante conclusión de que en poesía no hay reglas» (86). Véase también Aurora EgIDo, «Teoría de la égloga en el Siglo de Oro», Criticón, 30, 1985, 43-77. Carvallo, entre otros, afirma: «La Egloga es vna compostura común de la poesia exagematica y mista y dragmatica: porque vnas vezes se haze introduziendo personas que hablen, otras vezes habla el mismo poeta, como en Virgilio se puede ver». Cisne de Apolo, II Madrid, C.S.I.C., 1958, 103. Véase también, Alberto BlecuA, «Virgilio en Espana en los siglos XVI y XVI», Studia Virgiliana, Bellaterra, Servei de Publicacions de la Universitat Autonoma de Barcelona, 1985, 61-77, y el artículo de MARGHerTIA MORREAle en torno a Virgilio y la literatura castellana en Enciclopedia Vingiliana. Roma, Istituto dell'Enciclopedia Italiana, 1988, 956-75.

3 Sin entrar en la cuestión de si Cervantes era buen poeta quisiera señalar que sólo recientemente se ha despertado cierto interés acerca de su poesía, a pesar de que José Manuel Blecua, bajo el pseudónimo de JosePH M. ClauBe intentó hacerlo hace ya más de cuarenta anos en su estudio «La poesía lírica de Cervantes», en Homenaje a Cervantes. Madrid, Insula, 1948, 151-87. Después de aisladas tentativas de los años sesenta como el artículo de Eugeno Florr, aAlgunos comentarios sobre la poesfa de Cervantesx, Revista Hispanica Modeme, XXXIV, 1968, 262-75, es sobre todo a partir de las decadas de los 70/80 que empiezan a aparecer estudios espectficos como el de Elins L. Rrvers, "Viaje del Pamaso y poesía suelta», en Suma Cervantina citada 119-46, el de ADRINU LeWIS GalANRs, "Cervantes: el poeta en su tiempo», y el de ANDREs Amoros, «Los poemas en el Quijotex, los dos incluidos en Cenvantes, su obra y su mundo: Actas del I Congreso Intemacional sobre Cervantes (Madrid, Edi-6, 1981) 159. 178 y 707-15, el de MARY GAYLoRD RANDEL, «La poesía y los poetas en los Entremeses de Cervantes», Anales Cervantinos, XX, 1982, 173-203, el de Jose Lurs FERNANDEZ DE LA TORRE, aCervantes, poeta de festejos y certámenes», Anales Cervantinos, XXII, 1984, 9-41 y el de ADRINNR LASKarR MARTIN, «El soneto a la muerte de Femando de Herrera: texto y contexton, Anales Cervantinos, XXIII, 1985, 213-9. Véase también los comentarios de VICEnTE Gaos en la introducción de su edición de las Poestes completas de Cervantes (Madrid: Castalia, 1981). 
versos incluidos en su producción narrativa que, lejos de ser poemas compuestos con antelación y luego insertados sin más en la estructura de sus novelas, están relacionados estrechamente con la prosa y desempeñan funciones específicas dentro de la arquitectura general de cada obra 4 .

En este trabajo me propongo analizar las funciones narrativas y propiamente poéticas de la lírica presente en La Galatea, mostrando que, si bien en general se pueden aislar en otras novelas sui generis como la Diana y La Diana enamorada, en la obra cervantina son mucho más numerosas y elaboradas. Dichas funciones, dentro de la compleja estructura de la novela, contribuyen a crear el juego de perspectivas y contrapuntos que determina la originalidad cervantina dentro del género pastoril. En la actual revaloración de $\mathrm{La}$ Galatea emerge, entre otras cosas, la convicción de que su primera obra le haya servido al escritor como laboratorio literario en el cual se forjaría su genial arte novelístico posterior. Cervantes tenía evidentemente que superar la rígida dicotomía de la pastoril para encontrar el camino que llevaría a la novela moderna y la composición del Quijote no se realizó ex abrupto. Como senala López Estrada, «no hay contradicción entre ambos libros, sino continuidad» 5 .

\section{Las funciones de la poesía en La Galatea}

La fragmentada estructura de La Galatea ${ }^{6}$ carece, como es sabido, de un eje central o específico, como puede ser el palacio de la

\footnotetext{
- Con respecto a la alternancia de verso y prosa en las novelas pastoriles se encuentran observaciones en varios estudios, como en Los libros de pastores, 441-43 y 543-7, en La «Galatea» de Cervantes, 149-53 y en el reciente artículo de López Estrada, en el ensayo de Casalduero y en Pastoral Poetics, todos citados, pero ninguno de ellos se ha detenido en un análisis exhauśtivo del juego narratio que resulta de dicha alternancia. La única excepción digna de remarcar es la tesis doctoral de Alucia Perez Velasco, El díalogo verso-prosa en *La Galatea» de Cervantes, State University of New York at Stony Brook, 1989, que trata la cuestión desde una perspectiva bakthiniana. Al propósito cabe sefialar que hay todavía quien defiende la idea de que $\mathrm{La}$ Galatea sea una especie de cancionero o colección de poemas anteriores e intercambiables, como por ejemplo AmOROs en el artículo citado (713), pero al mismo tiempo se está creando una tendencia crítica que apoya la tesis opuesta. Casnudurro en su «La Galatea» cit., afirma tajantemente que «lo que es inaceptable y absurdo es imaginar que el género mixto era una manera cómoda de reunir unas cuantas poesías» (35) y Perez Velasco se sitúa en la misma línea.

5 LOPEz EsTradA, «La literatura pastoril y Cervantes: el caso de La Galatea, citado, 165.

- Para el presente estudio he utilizado la edición de La Galatea de Avalle-Arce. Madrid, Espasa-Calpe, 1987.
} 
sabia Felicia al que convergen todas las historias y los personajes de la Diana. Se constituye en dos planos narrativos distintos, el propiamente novelesco de las historias intercaladas y el pastoril de la sin par Galatea y de sus pretendientes, que se superponen y se mezclan, a lo largo de los seis libros, en un juego narrativo constante ${ }^{7}$. La alternancia de prosa y poesía funciona naturalmente en ambos niveles. Los personajes son muy numerosos, mucho más que en cualquier otra novela del género. Su continua y variada interacción constituye el motor narrativo, además de otorgar a la creación cervantina un dinamismo generalmente ausente en los libros de pastores. Las intervenciones poéticas pueden envolver un número oscilante de caracteres: pueden ser a una voz (monólogo), a dos (diálogos), a cuatro (cuarteto) y a muchas a la vez (corales o colectivas) según el contexto y la función que el autor les quiera otorgar. El monólogo, por ejemplo, resulta ideal para expresar las quejas de amor o el motus individual, mientras las intervenciones corales se emplean preferiblemente en las ocasiones mundanas de recreo y regocijo colectivo o de sabia plática teórica. En el primer libro prevalecen las composiciones a una o a dos voces, porque los personajes y las situaciones narrativas todavía se están esbozando. Sucesivamente, cuando ya se han acumulado suficientes elementos y la escena pastoril se encuentra bastante poblada, empiezan a utilizarse las intervenciones líricas colectivas. De hecho, el último libro es el que presenta la mayoría de los momentos corales. Concretamente, a lo largo de la narración, se interpolan tres poemas a dos voces (canto amebeo), cuatro cuartetos y dos composiciones colectivas, una de tema amoroso y otra lúdica, que llegan a emplear, respectivamente, hasta ocho y nueve voces en conjunto. Por supuesto, no todos los personajes poseen una voz poética; algunos sólo la tienen narrativa y otros se definen mayormente con una o con otra, según los casos. Por ejemplo, dentro del marco pastoril, la voz de Elicio, que es uno de los protagonistas, se eleva más a

7 De la estructura novelística y aspectos especificos de la arquitectura de $\mathrm{La}$ Galatea se han ocupado muchos. Vease, para citar algunos, a JENNIFER LOWE, aThe Cuestion de amor and the Structure of Cervantes' Galatea», Bulletin of Hispanic Studies, XIIII, 1966, 98-108 y KenNeTH P. Allen, aCervantes' Galatea and The Discorso intomo al comporre dei romanzi of Giraldi Cinthion, Revista Hispanica Modeme, XXXDX, 1976-77, 52-68 que parte de las consideraciones de Lowe para, en parte, refutarlas. Dentro de una bibliografía más amplia caben también Luis A. Murnuo, "Time and Narrative Structure in La Galatea», Hispanic Studies in Honor of Joseph H. Silverman. Newark, Delaware, Juan de la Cuesta, 1988, 305-17; Elizabeth RHOdes, «Sixteenth-Century Pastoral Books, Narrative Structure, and La Galatea of Cervantes», Bulletin of Hispanic Studies, LXVI, 1989, 351-60 y RUTH EL SAFPAR, \& La Galatea: the Integrity of the Unintegrated Text», en el citado Cervantes, su obra y su mundo, 345-53. 
menudo que la de cualquier otro, con once intervenciones; Erastro, Lenio y Lauso comparten el segundo eslabón en la escala de importancia poética con siete u ocho cantos ejecutados y, desde luego, hay también personajes puramente accesorios que, como Florisa y Aurelio, amiga y padre de Galatea, intervienen no más de una vez $^{8}$. Puede resultar interesante notar que generalmente no hay dúos mixtos entre hombres y mujeres. Semejante separación de los sexos caracteriza también la prosa. Sobre todo en los primeros libros si está narrando un personaje femenino, su público está constituido por mujeres, como en el caso de Teolinda que cuenta sus vicisitudes en presencia de Galatea y de Florisa, y, al revés, un hombre, como Silerio, habla de sus desventuras a un auditorio del mismo sexo. Más adelante, en cambio, las narraciones empiezan a ser mixtas y ocurren frente a un auditorio muy vasto que se ha ido ensanchando progresivamente 9 .

Toda intervención poética, como quiere la convención pastoril, se acompaña generalmente con el son de uno o más instrumentos musicales, en su mayoría rabeles y zampoñas, que otorgan a la novela un aire casi operístico o, en todo caso, teatral ${ }^{10}$. Además, no todos los poemas son simplemente cantados o recitados por sus autores. En muchos casos un personaje cita o recuerda los versos escritos por otros o lee un papel donde desesperados amantes han dejado anotados líricos pensamientos, escritos en momentos de suma tristeza, como en los casos de Mireno desconsolado por la traición de Silveria (220-3) y de Galercio que se ha enamorado de la cruel Gelasia (448-90). Completan la casuística los versos que Artidoro ha grabado en la corteza de un álamo blanco (137-9), topos virgiliano

8 Es notorio que muchos criticos han tratado de desenmascarar los personajes reales que, según sugiere el mismo Cervantes en el problogo de La Galatea (60), se esconderían disfrazados de pastores en las páginas de su novela, ScHevill y Bonmla, por ejemplo, antiguos editores de la obra (Madrid, Imprenta de Bernardo Rodriguez, 1914) reconocen, entre otros, en el difunto Meliso a Don Diego Hurtado de Mendoza, en Tirsi al poeta Francisco de Figueroa y en Lauso al mismísimo Cervantes (XXX-XXXI). Véase también La «Galatea* de Cervantes, de LOPEz EsTrADA (157-69) y Avalle-ArCE, en el prólogo a la edición citada (46-8). Para el tema especifico de la máscara y del disfraz en la novela pastoril cervantina remito a Groffrey StAGg, *A Matter of Masks: La Galatea», Hispanic Studies in Honor of Joseph Manson, Oxford, The Dolphin Book, 1972, 255-67.

- Pilar f. Caradas Greenwood en su artículo «Las mujeres en la semántica de La Galatea incluido en el citado Cervantes and the Pastoral, 51-61, analiza las diferentes modalidades de contar que caracterizarfan la narración femenina con respecto a la masculina.

10 Las relaciones que el género pastoril mantiene con las artes musicales y figurativas y con el teatro han sido repetidamente señaladas. Entre los ensayos más recientes que han tocado algunos aspectos de ese tema se pueden mencionar el artículo de Joan Cammarata y Bruno M. Damuni, «Music in La Galatea and the Visual Arts», Critica Hispanica, XI, 1989, 15-25. 
y ariostesco, y las cartas en verso, como la epístola de Timbrio a Nísida (199-204).

Por lo que se refiere a la tipología de las composiciones quisiera brevemente recordar que las canciones, los sonetos y los tercetos, es decir, la lírica italianizante, prevalecen y que, por el contrario, hay sólo un villancico. En La Galatea, por tanto, Cervantes sigue en líneas generales la práctica literaria contemporánea que prefiere la métrica culta italiana para los asuntos amorosos y pastoriles, dejando la lírica popular y cancioneril para otros contextos poéticos. Además, sin transgresiones notables, las canciones son de tema fundamentalmente amoroso, los tercetos se usan en la epístola de Timbrio a Nísida en la elegía fúnebre del libro sexto al pastor Meliso y en varias disertaciones. Finalmente, los sonetos se reservan para encerrar en la brevedad de la composición algún concepto o sentencia de varia naturaleza. A este propósito es interesante notar la intensificación del uso del soneto por parte del autor con respecto a las anteriores novelas pastoriles. En efecto, mientras que en la Arcadia italiana no se encuentra ningún ejemplo de dicha composición, en la Diana de Montemayor empieza a haber alguno, concretamente tres, y en la Diana enamorada de Gil Polo, para citar los posibles modelos cervantinos de mayor envergadura, ya se cuentan trece. Sin embargo, el autor de La Galatea eleva el número hasta veinte, más un soneto de Timbrio que se queda a medias - solo el primer cuarteto- en el gran momento del encuentro con el amigo Silerio, en el quinto libro ${ }^{11}$. En total, los poemas engarzados

11 A este propósito cabe señalar de paso que la lectura de los comentarios de Herrera a la poesía de Garcilaso pudo haberle estimulado a Cervantes la abundante práctica versificatoria del soneto que llevó a cabo durante toda su carrera literaria. Herreran efectivamente afirms con entusiasmo: «Es el Soneto la más hermosa composición, y de mayor artificio y gracia de cuanto tiene la poesía italiana y espanola. Sirve en lugar de los epigramas y odas griegas y latinas, y responde a las elegias antiguas en algún modo, pero es tan extendida y capaz de todo argumento, que recoge en si sola todo lo que pueden abrazar estas partes de poesiax, en Alberto Poroubras-Mayo, la teoria poética en el renacimiento y manierismo españoles. Barcelona, Puvill Libros, 1986, 105. Con respecto a las ideas poeticas cervantinas vease Porourras-Mayo, aCervantes y la teoría poctica» citado, y el apartado titulado «Poesía y principios generales» del trabajo de E. C. RneY, «Teoria literariax, en Suma Cervantina, citada, 295-302. Acerca de la métrica y de la tipologia versificatoria de la Galatea hay muchas observaciones esparcidas en la bibliografía de la novela cervantina. Quisiera sin embango señalar el trabajo de Alberto SANChez, aLos sonetos de La Galatea», que se encuentra incluido en $\mathrm{La}$ Galatea de Cervantes, cuatrocientos años despues, citado, 17-36. Además, J. M. Bubcun en aancilaso y Cervantes», Homenaje a Cenvantes, Madrid, Insula, 1948, 141-50, Euns L. Rivers en «Cervantes y Garcilaso», Cervantes, su obra su mundo, citado, 963-68, y Alberto Navarro Gonzlizz en aCervantes y Fray Luis de Le6n», Anales Cervantinos, X, 1971-2, 3-14, citan, de la novela pastoril cervantina, ejemplos de hurtos y parafrasis pocticos de los modelos favoritos del autor. 
en la arquitectura de la novela cervantina son unos ochenta y presentan mucha variedad incluyendo, además de las formas más frecuentes que ya hemos comentado, silvas, octavas reales, redondillas, una égloga representable y hasta una copla oncena, que canta Arsindo al final del libro tercero ${ }^{12}$.

Después de estas consideraciones de orden general, pasemos ahora a analizar las funciones que desempeñan las distintas intervenciones poéticas que, en un afán de sistematización, voy a distinguir en narrativas y poéticas propiamente dichas, teniendo en cuenta que, por supuesto, un poema puede tener distintas funciones a la vez y que aquéllas se contaminan recíprocamente ${ }^{13}$.

Desde el punto de vista estructural, una composición poética puede abrir o cerrar un libro, un episodio o un momento determinado de la novela. Es el caso del incipit de La Galatea que empieza con el canto melancólico de Elicio (65-6), o el del soneto que cierra la narración de Teolinda (141-2). Los libros, siguiendo una convención del género pastoril, acaban a menudo con la vuelta a la aldea de la compañía de hermosos pastores que se retiran, al anochecer, para reposar. Por el camino los personajes aprovechan para cantar y deleitarse colectivamente y la llegada corresponde en general al final del canto. Véase como ejemplo la conclusión del segundo libro: «Aquí acabó su canto Erastro, y se acabó el camino de llegar a la aldea» (195). Además de cerrar un segmento narrativo, el poema crea una pausa en la prosa que anticipa un cambio de escenario, de situación y de personajes, es decir, de enfoque novelístico. El principio de un libro es en efecto siempre distinto del final del que lo precede ${ }^{14}$. Otra obvia función estructural de la

12 Comenta muy oportunamente Fernandez-Canadas en Pastoral Poetics citado que, en un amplio sentido, «Variety... is a source of beauty and pleasure which Cervantes translated into a technique, his version of decorum which is expressed in his pastoral» (144).

13 Las funciones de la poesía en La Galatea no se han analizado muy detenidamente hasta ahora. Naturalmente, se encuentran observaciones esparcidas en la bibliografía especifica de la obra pero, en general se quedan en un nivel muy superficial. Por ejemplo en el artículo de MARY GAYLORD RANDEL, «The Language of Limits and the Limits of Language: The Crisis of Poetry in La Galateax, Critical Essays on Cervantes. Boston, Massachussets, G. K. Hall \& Co., 1986, 29-44, la autora se limita a señalar algunas, como el obvio valor emotivo de la poesía, como lenguaje del alma, y el «paradox of alluding to and simultaneously avoiding its fictional context» (35). También Pérez Velasco, en su estudio dialógico del juego narrativo de prosa y verso en la novela cervantina, aisla unos cuantos «cometidos» de los poemas (156-7).

14 A este propósito es interesante recordar que en La Galatea, contrariamente a lo que pasa en otras novelas pastoriles como la Diana de Montemayor, la secuencia de los libros no corresponde exactamente a la alternancia de días y noches, es decir, el final de un libro no coincide con el anochecer, ya que todo en la 
poesía es la de fragmentar la narración para crear un dinamismo lingüístico que acompaña el movimiento de los personajes que se desplazan continuamente de un lugar a otro, algunos sin más objetivo que el de apacentar el ganado y de deleitarse con el canto, otros estimulados por el deseo de topar con el bien amado ${ }^{15}$. Opuesta a la pausa y también creadora de dinamismo vital es la internupción que, en numerosas ocasiones, deja a medio decir los versos que los personajes están cantando en una determinada ocasión. Además del ya mencionado soneto de Timbrio (348), que se canta íntegramente sólo cuarenta páginas más adelante (384), cabe recordar la festiva circunstancia del libro sexto donde el juego de las adivinanzas se internumpe por la llegada de unos pastores, que publican el fracasado intento de suicidio de Galercio (481). Hacia el final del libro quinto encontramos también la imposibilidad para Orompo, Crisio, Orfinio y Marsilio de cantar lo que tenían planeado por un ruido imprevisto, anunciando la llegada del desamorado Lauso, que les fuerza a «bolver las cabezas» (386-7). La interrupción prosa-verso es recíproca y representa una evidente tentativa del autor de reducir, en cuanto sea posible, la gran distancia que se mantiene entre la idealización del mundo pastoril y la realidad de las historias novelescas ${ }^{16}$.

Desde el punto de vista argumental las funciones de las zonas líricas intercaladas son mucho más numerosas y sutiles; se relacionan siempre con la prosa que las precede o sigue. En el caso en

novela cervantina se transforma y cambia con respecto a los modelos. Del tiempo y de la estructura de la novela hablan específicamente LUIS A. MURILLo, «Time and Narrative Structure in La Galatea», citado y AURORA EgIDo, "Topografía y cronologia en La Galateaw, Lecciones Cervantinas, Zaragoza, Caja de Ahorros de Zaragoza, Aragón y Rioja, 1985, 49-93.

is La función narrativa del deseo ha sido estudiada por STEven Hutchinson, en «Desire Mobilized in Cervantes' Novels», Joumal of Hispanic Philology, 14, 1990, 159-74. Véase además «Cervantes y la teoría renacentista del deseo», de Edgar Paiewonsky-Conde, Anales Cervantinos, XXIII, 1985, 71-81.

16 Acerca de la interrupción cervantina, Forcione comenta «El lector no tarda mucho en sentir que el autor de La Galatea tiene una obsesión con lo interrumpido o truncado; y si conoce bien la narrativa y la teoría literaria del Renacimiento, no tarda en advertir que Cervantes está experimentando audazmente con las famosas técnicas de Heliodoro: fragmentación del argumento, suspensión por medio de la limitación del punto de vista, aclaraciones restrospectivas de hechos sorprendentes que se desarrollan ante los ojos de un lector asombrado, deslumbrado y a menudo frustrado», en «Cervantes en busca de una pastoral auténtica», citado, 1022-3. Cabe señalar que la interrupción anda pareja con la violencia que irrumpe en las páginas de la novela cervantina. De esa caracteristica de La Galatea se ha ocupado específicamente BARBArA MuJCA en dos articulos: «Antiutopian Elements in the Spanish Pastoral Novel», Romance Quarterly, 26, 1979, 263-82 y «Violence in the Pastoral Novel from Sannazaro to Cervantes», Hispano-Italic Studies, 1, 1976, 39-55. 
que el poema preceda la narración, éste suele introducir al lector a un personaje o una situación de la que sucesivamente se darán muchas noticias a través de los relatos de los protagonistas. En el primer libro, por ejemplo, después de matar a Carino, Lisandro se queja cantando unos versos en los que alude a la muerte de su amada, al delito y traición del contrincante y a su personal desesperación. Antes de que el desdichado pastor haya podido explicar a Elicio las razones que lo han llevado al brutal asesinato, se anticipa el núcleo temático de la historia que se va luego a contar pormenorizada. Además, el resultado de este lamento poético es el de aumentar la curiosidad del que lo está escuchando e, implícitamente, del lector: «Aquí cessó la voz, pero no los sospiros del desdichado que cantado avia, y lo uno y lo otro fue parte de acrescentar en Elicio la gana de saber quién erax (83). Con lo cual vamos a dar con otra función poética, la de crear expectativa acerca de lo que sigue. En la novela cervantina la prolepsis poética se utiliza cada vez que se va a introducir una nueva historia. Teolinda aparece en el escenario pastoril primero quejándose en voz alta de su «cruda hermana» y del «desamorado pecho» de Arsildo, luego reiterando sus lamentos en los versos de *una copla antigua» (104-5) y finalmente narrando su historia a las pastoras Galatea y Florisa. De la misma manera, Silerio, en el segundo libro, anuncia su llegada con el sonido de un harpa y con una silva en la que se nombran al amigo Timbrio y a la dulce «enemiga» Nísida (158-61) ${ }^{17}$. Sin embargo, la anticipación no tiene necesariamente que referirse a una historia y puede sin más introducir a un nuevo personaje, esbozando aspectos de su carácter y de su vivencia. Por ejemplo, la canción de Elicio, además de constituir el exordio de la novela ${ }^{18}$, pre-

17 La creación de la suspensión para suscitar la curiosidad del oyente, según los preceptistas del tiempo, es un recurso típicamente teatral. Veamos, por ejemplo, lo que afirma Carvallo en la «Doctrina Teatral» de su poética: «En la epitasis, que es la segunda parte, como existencia de la comedia, hanse de proseguir la materia con diferentes sucesos de los que se pudieran pensar y otros varios y revueltos casos, como haciendo nudos, procurando tener siempre el ánimo de los oyentes suspenso, ya alegres, ya tristes, ya admirados, y con deseo de saber el fin de los sucesos» (521), lo cual, como se sabe, refleja lo que Lope de Vega, a distancia de pocos ańos, dictaminó en su «Arte nuevo de hacer comedias». Cito de la edición crítica de Poroueras MaYo del «Diálogo Tercero, parágrafos 1-6 [Doctrina Teatral] del Cisne de Apolo», incluida en Homenaje a Alberto Navarro. Kassel, Ed. Reichenberger, 1990. Volviendo a Cervantes, se puede observar que la frecuencia con la que se vale de este recurso refuerza la presencia de elementos teatrales en La Galatea.

is Aún dentro del marco teatral que se puede senalar en La Galatea, dicha intervención de Elicio, que abre de entrada la novela, puede acercarse al faraute que, como afirma Carvallo, sirve para «declarar el argumento» (523) de una obra. Efectivamente, el pastor se presenta quejándose de su condición de amante infeliz, 
senta la tópica condición de enamorado infeliz que caracteriza al pastor, y el soneto con el que Galatea entra en la escena afirmando *no temeré en segura parte / de amor el fuego, el lazo, el dardo, el yelo» (101) define al personaje en su papel de mujer fría e insensible al sentimiento amoroso.

Cuando el poema sigue a la narración las funciones que desempeña son obviamente de orden opuesto a las que acabamos de señalar, es decir, resume en sus líneas esenciales lo que se ha contado en la prosa. También pueden añadir algún elemento nuevo a una situación o personaje ya conocido, de modo que en el quinto libro, antes de que Galatea exprese sus quejas poéticas acerca del matrimonio que su padre Aurelio ha concertado contra su voluntad, en el marco narrativo ya se ha dado la noticia con numerosos detalles a ravés de una plática de Elicio y Damón. Las redondillas de la pastora simplemente reiteran el drama que la concierne y expresan sus temores sobre el incierto futuro que su condición de malmaridada y la lejanía de la patria le van a deparar (373-75). Asimismo, el papel de Galercio a Gelasia, que Tirsi lee públicamente después de rescatar al pastor de las aguas donde intentaba ahogarse, sintetiza su condición y comenta la indiferencia de la orgullosa pastora que lo ha llevado al borde de la aniquilación (488-90). La canción que Lenio canta al final del quinto libro, asombrando a cuantos lo están escuchando, revela un cambio esencial en la caracterización del personaje hasta entonces conocido como el pastor desamorado, ya que los versos descubren sin velos su repentino cuanto desesperado enamoramiento de la inalcanzable Gelasia (399-400).

En muchas ocasiones las intervenciones líricas se oponen a la narración que las sigue o precede creando un contrapunto estructural o temático. En el primer libro, Erastro y Elicio se exhiben en un canto amebeo «para señal de nuestro buen propósito y verdadera amistad (73) que contrasta evidentemente con el episodio que va a seguir en la prosa, es decir, el asesinato de Carino por mano de Lisandro. La armonía poética y espiritual de los pastores deja lugar al sentimiento contrario, la violencia y el deseo de venganza de los otros dos personajes. Con respecto al contenido el ejemplo más claro de contrapunto lo representan las intervenciones de Lenio, que aparece siempre en la escena pastoril para hablar y cantar mal del amor, justo después de que algún personaje acabe de confesar

estado compartido por muchos de los personajes que llenan las páginas de la novela, introduce, describiéndolo, el paisaje pastoril y anticipa casi literalmente los conceptos que Galatea, su contrincante amorosa, expresará en el soneto que acompaf́a su aparición en la escena bucólica. Los versos de Elicio acaban con ala saeta, la red, el lazo, el fuego» (66) y los de Galatea empiezan con «Afuera el fuego, el lazo, el yelo y flechas (101). 
su enamoramiento. En el primer libro su intervención sigue la historia de Teolinda que estaba comentando a las pastoras la ocasión en que descubrió que Artidoro compartía sus sentimientos amorosos (119-22). En el segundo aparece cantando sus invectivas mientras Silerio relata sus esfuerzos para convencer al amigo de que no estaba enamorado de Nísida. En el libro siguiente se pone a cantar unas octavas reales acerca de la perfidia del amor, justo después de que Mireno se ha marchado desesperado por las bodas de su antigua prometida Silveria. En el cuarto vuelve a reiterar sus vituperios contra el niño ciego hasta que, al final del quinto libro, aparece, sorprendentemente, cantando al amor, inmediatamente después de la llegada del desamorado Lauso.

Una función parecida a la que acabamos de señalar es la de los comentarios en verso que acompañan un diálogo o un acontecimiento. Al terminar el primer libro Florisa reflexiona, cantando un soneto, acerca de la contienda verbal en que ha visto a Elicio y a Lenio contrapuestos: «Éste mil bienes del amor pregona; / aquél publica dél vanos cuidados; / yo no sé si los dos andan perdidos, / ni sabré al vencedor dar la corona: / sé bien que son de amor los escogidos / tan pocos, cuantos muchos los llamiados» (126). En este caso el poema sigue una narración y, de cierta manera, es una consecuencia del mismo. Al contrario puede verificarse que un diálogo en prosa se origine por el estímulo de una intervención lírica que provoque la reacción inmediata de algún personaje. En el cuarto libro, por ejemplo, Damón presta su voz a los versos de Lauso que poetizan el topos del menosprecio de corte y alabanza de aldea y Lenio, al final, los alaba comentando que su poesia preferida es la que precisamente no trata de las cuestiones de amor (288-293).

Para terminar el análisis de las funciones narrativas de la lírica intercalada, quisiera señalar la posibilidad de anticipar o incluso facilitar la anagnórisis entre los personajes por medio de unas intervenciones poéticas. Me refiero naturalmente al encuentro de los dos amigos y de sus respectivas prometidas que pone fin a sus innumerables peripecias. Como sabemos, Silerio se está desesperando en una solitaria ermita sin saber que a unos pasos se encuentra su amado Timbrio con todos los demás pastores y personajes que le rodean. En orden sucesivo se ponen a cantar Nísida, Damón y Timbrio, con la intención de revelar su presencia al dolorido Silerio para prepararlo gradualmente al gran encuentro; y es sólo cuando la voz de Timbrio entona los primeros versos que el ermitano sacude su tristeza y sale a abrazar al amigo.

Antes de pasar a las funciones poéticas quisiera brevemente mencionar el valor teórico y filosófico que la poesía presenta en el contexto pastoril. Diríase que se encuentra a medias entre las dos 
categorias de funciones que estoy tratando de delinear. En efecto, la docta disertación, generalmente de asunto amoroso, ocupa un lugar de importancia primaria en la novela de pastores y La Galatea no representa ninguna excepción. Cabe por supuesto citar, a este respecto, la larga égloga teatral montada en el libro tercero para celebrar las bodas de Daranio y Silveria (239-52), además de recordar que cada personaje al hablar o cantar del amor expresa, de alguna manera, conceptos reconducibles a las teorías neoplatónicas. Un caso que se puede reconducir a dicha categoría es el de la glosa que Elicio canta en el primer libro, en la cual se alude al amor como causa primera (122-3). De hecho, los pastores representan la casuística amorosa personificada, que Cervantes pudo sacar ya sea de los Dialoghi d'Amore, ya sea de Gli Asolani o de cualquier otro tratado contemporáneo sui generis ${ }^{19}$.

Nos quedan entonces por analizar las funciones poéticas propiamente dichas. La más frecuentemente utilizada, por supuesto, es la que expresa toda clase de sentimientos: tristeza, desesperación, melancolía, congoja, incertidumbre, perplejidad, alegría, desilusión, esperanza, quejas y celos. No faltan ni los vituperios, aunque se limiten al caso del desamorado Lenio. Cada intervención lírica lleva implícita dicha función, a la que se superponen casi siempre otras, con las únicas excepciones de las disertaciones teóricas sobre los casos de amor, y por esta razón no hace falta citar ejemplos específicos. Quizás sólo valga la pena recordar que, de acuerdo con las convenciones del género pastoril, los lamentos y las quejas de los enamorados infelices constituyen la nota dominante de la novela. Todos los personajes en un momento dado tienen ocasión para desesperarse: Elicio

19 De los tratados amorosos y de las teorías neoplatónicas que dejaron huellas más o menos evidentes en las páginas de La Galatea, se han naturalmente ocupado todos los grandes cervantistas. Baste recordar el ya mencionado El pensamiento de Cervantes de AMérico CASTRo que dedica un capítulo especificamente a *La naturaleza como principio divino e inmanente», 159-81, La «Galatea* de Cervantes de LÓPEZ EsTradA, 85-115 y el artículo de GeOfFrey STAGg, «Plagiarism in La Galatea», Filología Romanza e Letteratura, 6, 1959, 255-76. De la más reciente proliferación bibliográfica se puede mencionar, entre muchos, el artículo de JOHN T. CuLL, «Another Look at Love in La Galatea*, en Cervantes and the pastoral, citado, 63-79 y señalar sobre todo el ensayo de ANDRés SORU OLMEDO, Los Dialoghi d'Amore de León Hebreo: aspectos literarios y culturales. Granada, Universidad de Granada, 1984, que analiza en un breve apartado las relaciones existentes entre el tratado de León Hebreo y la novela pastoril española. Por lo que se refiere, en cambio, a la posible herencia aristotelica en La Galatea, vease el trabajo de TerRsA Herraz, «Dos imágenes del amor en Cervantes», Comunicaciones de literatura española, 1, 1972, 109-15. Entre los numerosos juicios en esta materia, el de Avalle-Arce, en La novela pastoril espantola ya citado, defiende que el convencionalismo amoroso de la pastoril en La Galatea ase empapa de vida concreta* y que el neoplatonismo, en las cultas discusiones de los pastores, en varios puntos se invalida (240-1). 
por el desdén de la amada, Lisandro por la crueldad del sino, Teolinda por la traición de la hermana, Galatea por el matrimonio inoportuno, Mireno por el abandono de Silveria y así por el estilo. También, una composición que ejemplifica una idea teórica puede al mismo tiempo expresar sentimientos, como en el caso del soneto de Gelasia incluido en el último libro. En efecto, la pastora defiende con pasión la libertad y la independencia de las cadenas amorosas en un poema que, como ha sido oportunamente señalado, ejemplariza el tema literario de la vida retirada ${ }^{20}$.

La segunda función poética que más a menudo recurre en $\mathrm{La}$ Galatea es la celebrativa que, específicamente, comprende el panegírico, la elegía, el epitalamio y la épica laudatoria. Ejemplos de poemas panegíricos son los que cantan los enamorados pastores exaltando la belleza del bien amado, entre otros, las octavas reales de Elicio y Erastro alabando a Galatea (73-6) y la canción de Silerio celebrando la "perfección soberana" (177) de Nísida. Al principio del sexto libro Tirsi, Damón, Elicio y Lauso, sin la ayuda de instrumento alguno, entonan una elegía para el difunto pastor Meliso, exaltando la memoria del muerto y pregonando su gloria eterna $(411-8)^{21}$. De tono y ritmo opuestos son obviamente los poemas que acompañan las bodas de Daranio y Silveria de los cuales la copla oncena, que Arsindo entona para la ocasión, es un ejemplo de rústico epitalamio (262-4) ${ }^{22}$. Finalmente, el Canto de Calíope, como es archisabido, celebra cien ingenios poéticos contemporáneos de Cervantes de los que muchos, hoy día, son prácticamente desconocidos. Dicha composición, en cuanto épica laudatoria, representa por un lado una pieza casi de rigor en el género pastoril, y por el otro una concesión del autor a la realidad histórica que le obligaba a buscar protección literaria y política ${ }^{23}$.

La siguiente función que voy a señalar es la lúdica que, en parte, cabe también dentro de otras categorías. Lo lúdico, en la litera-

20 Florrt, «La poesía de Cervantes», citado, 271.

21 La elegía acompaña naturalmente al llanto que es un elemento muy recurrente de las novelas de pastores. Al propósito véase JeANNe C. WALlace, «El llanto como elemento dramático en La Galateax, en Cervantes and the Pastoral, citado, 185-95.

22 Para el epitalamio en la pastoril española remito al artículo de THomas Deveny, «The Pastoral and the Epithalamium of the Spanish Golden Agex, en Cervantes and the Pastoral, citado, 81-99.

${ }^{23}$ La bibliografía relativa al Canto de Calíope es particularmente abundante. Para juicios sobre las razones que le animaron posiblemente a Cervantes a la composición de este canto véase a MARCEL BatallLoN, «Relaciones literarias», Suma Cervantina, citada, 215-32 y a Pilar Fernandez-CaNadas de Greenwood, «Los médicos del "Canto de Caliope" ", Quademi Ibero-Americani, 57-8, 1984-5, 1-19. En cambio para informaciones específicas acerca de los ingenios celebados por la pluma cervantina, mantienen en general su validez las notas que ScHevil y Bonmu añadieron en la edición mencionada de la novela cervantina, 285-361. 
tura pastoril, que ya de por sí se presenta como un género deleitable, se relaciona ya sea con la celebración festiva del epitalamio que acabamos de mencionar, ya sea con el escenario arcádico en el cual se regocijan y encuentran los pastores. Este último, que es separado del espacio de la acción novelesca, representa el contenido ideal de juegos y pasatiempos. Por esta misma razón la función lúdica de la poesía implica siempre un contexto ameno y colectivo. En La Galatea aparecen varios momentos de recreación mundana: la ya recordada égloga teatral, el juego de los enigmas o adivinanzas (474-81), que ve la participación de ocho personajes, y el certamen poético que se celebra al final del libro tercero con las glosas de Francenio y Lauso (260-1). A estas ocasiones hay que añadir los amenos poemas líricos de distintas voces, por ejemplo el canto amebeo de Damón y Tirsi, que divagan acerca de la ausencia y del desdén de las respectivas amadas (143-7), la intervención coral de Elicio, Marsilio, Erastro, Crisio y Damón que, justo después del Canto de Calíope, razonan acerca de la fe amorosa (461-73) y las canciones que los pastores entonan para entretenerse cuando se desplazan de un lugar a otro que, como hemos visto anteriormente, pueden desempeñar también otros papeles.

Dos funciones poéticas estrictamente relacionadas a las teorias neoplatónicas son las que voy a definir como catártica y mayéutica. Empecemos por la primera. En el ambiente literario bucólico, como sabemos, los pastores son siempre excelentes músicos y poetas; a cada rato están tañendo sus instrumentos listos para lucirse en uno de los poemas que forman su extenso repertorio lírico. Lo que más llama la atención es que dicha habilidad se muestra incluso en las circunstancias menos adecuadas para la diversión musical, como en el caso de Lisandro que, después de matar a Carino, alterna los suspiros y lamentos con el canto. Además, su agitado y desasosegado estado de ánimo contrasta netamente con su «suave y acordada voz» (81). Por supuesto, nos encontramos en un contexto literario altamente convencional pero, al mismo tiempo, es oportuno relacionar esta aparente paradoja con la concepción neoplatónica, de origen pitagórico, que considera la música terrenal como manifestación fenoménica de la melodía celestial de las esferas. Según esta visión el canto presenta una función catártica permitiendo al pastor volver en contacto con la armonía universal, a pesar de que, en su vivencia histórica, aquélla se haya quebrado de manera definitiva ${ }^{24}$. La función mayéutica de la poesía se define, por su parte, con respecto a Erastro. Este per-

24 Acerca del poder benéfico de la música Cammarata y Damani, en «Music in La Galatea and the Visual Arts», citado, recuerdan: "The beneficial effects of song and music on the spirit of man were reiterated in the Renaissance, under the Neoplatonic influence of Marsilio Ficino, by such respected musicologists as 
sonaje, como Avalle-Arce nos ha aclarado ${ }^{25}$, representa el tipo rústico del pastor que, gracias al amor por Galatea, se expresa de forma que su baja condición de otra manera no le consentiría. El amor y el canto, que transmiten los sentimientos, son entonces los maestros que le llevan a adquirir clara conciencia de los conocimientos que se le forman en la mente. A este proposito puede ser interesante notar que en el primer libro Erastro no interviene poéticamente sino una vez, junto a Elicio, y, en dicha ocasión, se deja guiar por el enamorado y culto compañero que abre y cierra el canto amebeo. En el segundo libro el pastor sigue escuchando, como espectador, primero las canciones de Damón y Tirsi y, sucesivamente, los versos de Elicio; luego participa en un cuarteto canoro junto a los tres personajes mencionados y es sólo al final del libro que entona unas redondillas a solas en las que, alabando la belleza de Galatea, pone en práctica la lectio que la poesía y el amor le han enseñado.

El poder mayéutico de la poesía en realidad no es sino un aspecto específico del poder persuasivo de los versos, como vehículo

Enriquez de Valderrábano in the Prologue to his Silva de sirenas (Valladolid, 1547) and Juan Bermudo in his Declaración de instrumentos (Osuna, 1549-1555) (16). Veamos, para ejemplificar, algunas de las afirmaciones de Bermudo acerca del poder de la música: «Es cosa común, dice Boecio en el libro y capítulo primero, el canto destruir los vicios, y perfeccionar muchas cosas, así en los cuerpos, como en las almas. (...) Persuade la clemencia, destruye y destierra los cuidados, reprime las iras, cria las artes, y favoresce la concordia. (...) En confirmación de lo ya dicho tiene Avicena, que la Música aprovecha para mitigar todo dolor». Cito de la edición facsímil de Macario Santiago KASTNER. Kassel y Basel, Bănenreiter Verlag, MCMLVII, fol. VII [he modernizado la grafía]. Veamos asimismo lo que dice Mursiuo Ficino a propósito de la relación entre armonía universal y la música en El libro dell'amore. Firenze, Leo O. Olschki Editore, 1987: «per quella velocissima e ordinatissima conversione de' cieli, stimiamo nascere consonantia musicale, e per otto moti d'otto cieli otto tuoni, e da tutti insieme uno concerto producersi. Adunque e nove suoni de' cieli chiamiamo nove muse per cagione della musicale concordia. L'animo nostro da principio fu dotato della ragione di questa musica, e meritamente, essendo l'origine sua dal cielo. Dentro a llui è nata la celeste armonia, la quale poi imita e mette in opera con varii canti e instrumenti» (108). Véase también su teorfa del furor: «Certamente l'animo non pud ad essa unita tornare se egli e caduto nel corpo, in operationi varie distracto e inclinato all'infinite moltitudini delle cose corporee, il perché le sue parti superiori quasi dormono, l'inferiori soprastano all'altre. Le prime di sonno, le seconde di perturbationi sono piene, e insomma tutto l'animo di discordia e dissonantia è pregno. A dunque principalmente ci bisogna el poetica furore, el quale per tuoni musicali desti le parti che dormono, per la suavità armonica addolcisca quelle che sono turbate, e finalmente per la consonantia di diverse cose scacci la dissonante discordia e le varie parti dell'anima temperi. (213). De la influencia de Ficino en León Hebreo, y no sólo por la idea de la armonía y de la música, trata SORIn OLMedo en Los Dialoghi d'amore de León Hebreo: aspectos literarios y culturales, citado.

25 Prólogo a la edición citada de La Galatea: «Pronto se poetiza Erastro, pues no tandamos en enteramos que el también está preso en la red definitoria de Amor, Naturaleza y Fortuna» (16). 
de sentimientos, que se manifiesta de muchas formas. En varias ocasiones, para citar un ejemplo, un personaje, que generalmente pertenece al espacio novelístico, cita o canta un poema que en alguna ocasión le ha proporcionado alguna ventaja o le ha permitido conseguir un objetivo muy concreto. En la historia de Teolinda la pastora menciona una sextina que alusivamente le permitio entender que sus sentimientos eran compartidos: «tomé yo ocasión de imaginar si por ventura mi vista algún nuevo accidente amoroso en el pecho de Artidoro había causado» (118-9), pero es sobre todo Silerio quien recurre en gran medida al poder sugestivo de la poesía. A lo largo de su narración nos enteramos sucesivamente de que, para mostrar a Timbrio que iba a poder disfrazarse con éxito de truhán, le entona un villancico (174-5); a fin de lograr la libre entrada en la casa de Nísida se gana la afición de sus padres gracias al canto (177-8) y, finalmente, para convencer al amigo de que él no está enamorado de la muchacha recurre a unas coplas reales, que había escrito efectivamente para Nísida, haciéndole creer que están dirigidas a la hermana Blanca.

Una fünción que se encuentra a medio camino entre lo poético y lo narrativo es la de la descripción. Por supuesto, no se trata de la representación realista de lugares y personajes, sino del uso de trilladas metáforas e imágenes para retratar la belleza angelical de las pastoras, como en los versos de Elicio y Erastro en alabanza de Galatea, y para esbozar el convencional paisaje bucólico que funciona como teatro de la novela.

La última función poética en la que quisiera hacer hincapié es, sin duda alguna, la menos utilizada en La Galatea. Me refiero a la función irónica que, en el resto de la producción cervantina en prosa resulta, en cambio, fudamental. Aparentemente la novela pastoril no presenta rasgos irónicos ni mucho menos burlescos. La obra de Cervantes, en general, respeta la convención del género. Pero una atenta lectura del texto nos permite individualizar unos rasgos muy sutiles que, con un poco de aproximación, podrían caber dentro de dicha categoría. Uno de estos toques imperceptibles de la ironía cervantina todavía en germen ha sido señalado por Maxime Chevalier y se refiere a la kinsólita» mención de la suegra por parte de Galatea en las redondillas que expresan su tristeza por el matrimonio a deshora. Semejante referencia a una de esas «personillas caricaturescas que invaden la literatura alrededor de 1600 en el contexto pastoril ha justamente llamado la atención del agudo estudioso ${ }^{26}$. Sin embargo, hay por lo menos orra situación que se pue-

26 Maxime Chevaline, aLa antigua enfadosa suegrax, La Galatea de Cervantes cuatrocientos años después, citado, 103-9. 
de leer en clave ligeramente irónica y que deja entrever al autor omnisciente que por un momento se cansa de su compostura pastoril. Se trata de la escena en la que Lenio aparece por primera vez en las páginas de la novela para resumir en un soneto sus vituperios contra el amor. El tono de los versos contrasta decididamente con el contexto pastoril, que se alimenta de ese sentimiento tan vituperado, al punto que los juicios excesivos del personaje rozan la parodia. Según Lenio, el amor sería «Un vano, descuidado pensamiento, / una loca altanera fantasía, / un no sé qué, que la memoria cría, / sin ser, sin calidad, sin fundamento» (121), donde el «no sé qué», lejos de referirse a lo inefable del sentimiento amoroso, funciona como un sinónimo de «descuidado pensamiento» y de *altanera fantasía ${ }^{27}$. Esta nota antiutopística del poema de Lenio continúa reforzándose en el segmento en prosa que sigue inmediatamente. En este pasaje el pastor desamorado llega casi a punto de pelearse con Erastro que pierde literalmente la paciencia frente a los vituperios pronunciados por el contrincante (125) ${ }^{28}$. Cervantes evidentemente no explota en La Galatea a las posibilidades de la función irónica de la poesía, para no alejarse demasiado del género en el cual había deseado experimentar su ingenio primerizo, pero deja sin embargo entrever alguna de sus potencialidades.

De todo lo que hemos estado diciendo hasta ahora podemos sacar unas primeras conclusiones. Por un lado, los versos de la primera obra cervantina están siempre cuidadosamente insertados en la narración y no sólo para cumplir con las exigencias del género mixto. Cada intervención poética desempeña una o más funciones ayudando a crear la difracción de perspectivas y la complejidad de la estructura novelística. Por otro lado, el uso de la poesía cumple con las funciones que, según el escritor, caracterizan el arte narrativo: admirar o suspender, deleitar o entretener y finalmente instruir ${ }^{29}$.

27 Para más detalles sobre «El "no se que" en la literatura espanola», vease Alberto Poroueras-Mayo, Temas y formas de la lieratura española. Madrid, Gredos, 1972, 11-59. El autor cita y recoge varios casos de la conocida fórmula en la obra de Cervantes.

28 A mi parecer, Lenio, como carácter, tiene algo, aunque vagamente esbozado, del gracioso del teatro áureo y no sólo por la escena que acabo de mencionar. Su función primaria de aparecer casi siempre al final de los libros para oponerse a modo de contrapunto a los demás personajes, presentando la otra cara de la medalla de la realidad pastoril, representa de hecho una de las múltiples funciones del gracioso barroco. Además si situamos al personaje en el contexto semiteatral de la novela pastoril la observación parece encontrar mayor crédito.

29 Para más detalles remito al estudio fundamental de RnEY, Teoría de la novela en Cervantes, citado. Puede resultar interesante, además, confrontar la tipología de las funciones poéticas que hemos individualizado en La Galatea con las que 


\section{Las funciones de la poesía en los modelos del género pastoril}

Antes de terminar, quisiera brevemente hacer algunas consideraciones acerca del uso de la lírica en la Diana de Montemayor y en la Diana enamorada de Gil Polo, que constituyen los modelos españoles del género pastoril, para compararlo con lo que acabo de señalar a propósito de La Galatea . Para realizar un trabajo exhaustivo habria naturalmente que incluir en el estudio las numerosísimas novelas sui generis que se compusieron antes de la obra cervantina, por ejemplo, las de Alonso Pérez y Gálvez de Montalvo, pero esto ya va más allá de los propósitos del presente trabajo. Además, como dichas novelas no son sino una imitación de las iniciadoras del género que casi nada añaden a su convencionalidad, prefiero limitarme a rápidas observaciones de las obras arquetípicas.

Una atenta lectura de Los siete libros de la Diana y de la Diana enamorada revela que muchas de las funciones que hemos individuado en la novela cervantina ya están presentes en los modelos anteriores. Sin embargo se puede notar que, paralelamente al complicarse y al fragmentarse de la arquitectura general de la obra, el empleo de la poesía en La Galatea se vuelve más complejo y matizado, además de comprender nuevas funciones. En los dos modelos la relación que se plantea entre la prosa y el verso es mucho más sencilla, el número de poemas intercalados es decididamente menor y la conexión de las intervenciones líricas con la estructura narrativa resulta ser realmente más convencional que dictada por las necesidades de la técnica novelística. Las funciones poéticas que predominan en la novela de Montemayor ${ }^{30}$ son específicamente la lúdica $o$ de entretenimiento, la teórica, la celebrativa, que comprende el canto de Orfeo (278-93) y los panegiricos a la belleza de las damas, la propiamente poética de expresar sentimientos, lamentos y quejas especialmente, y, finalmente, la persuasiva que se explicita, por ejemplo, en el enamoramiento de Belisa por Arsileo que le cantaba versos por parte de su propio padre Arsenio. Entre las funciones narrativas se pueden individuar la de abrir y cerrar convencionalmente los libros y la de añadir algunas informaciones a lo narrado en prosa, como en el caso de la ninfa Dórida que, en el segundo libro,

Carvallo elenc6 en la «Doctrina Teatral», citada. El preceptista, al hablar de los tres géneros poéticos en que, según el, se clasifica la poesía -dramática, exagemática y mixta - afirma: aY en estas tres maneras se suele loar, vituperar, formar quejas, dar disculpas, consolar, dar parabien, hacer gracias, pedir, contradecir, confirmar, persuadir, exhortar, hacer elegias, epigramas, enigmas, padrones, epitafios, escribir, contar y otras semejantes maneras y formas de decir» (515).

30 Las citas y referencias a Los siete libros de la Diana proceden de la edición de Asunción Rallo. Madrid, Cátedra, 1991. 
recuerda en verso las vicisitudes de Silvano, Sireno y Selvagia que ya habían sido anticipadas por los mismos protagonistas (171-85). La estructura de los libros es muy sencilla y queda claro que a Montemayor no le interesa disfrutar, como hace Cervantes, todas las posibilidades del juego prosa-verso ${ }^{31}$. El primer y el segundo libro de la Diana se abren con amplias introducciones líricas cantadas por los tres protagonistas y se cierran con intervenciones convencionales de los mismos, después de un largo segmento narrativo. El libro tercero presenta una estructura aún más lineal, ya que todas las intervenciones poéticas se engarzan en la narración de Belisa que ocupa íntegramente las páginas del mismo. Los demás tampoco presentan arquitecturas mucho más complejas.

Gil Polo, por su parte, modifica ligeramente la estructura y las coordenadas fijadas por Montemayor atribuyendo una gran importancia a la función celebrativa de la poesía. Con respecto al modelo, la Diana enamorada ${ }^{32}$ se compone sólo de cinco libros de los cuales el último está totalmente dedicado a los festejos que se organizan en la refinada residencia de Felicia después de que cada pareja se ha juntado felizmente y las peregrinaciones de los personajes han encontrado su inesperada conclusión. Las funciones narrativas son aproximadamente las mismas que en la Diana, pero se añaden un certamen lírico, constituido por el canto amebeo de Sireno y Arsileo (247-53), un epitalamio en «versos franceses» para las bodas de Diana y Sireno (260-2), la lírica piscatoria de Nerea, entonada en ocasión de la anagnórisis que se produce entre Clenanda y sus hermanos (195-201), y el entretenimiento cortesano de las adivinanzas que tiene lugar en el quinto y último libro (280-287).

Por lo que hemos estado analizando anteriormente a propósito de La Galatea, resulta evidente que Cervantes se vale de la experiencia de los predecesores trasformándola y adaptándola a su gusto y originalidad narrativa ${ }^{33}$. Con respecto a las funciones poéticas, se

31 Señala Avalle-ArCe en La novela pastoril española que a Montemayor le interesaba el análisis del sentimiento amoroso (81) y que su técnica narrativa no es por esto primitiva (91).

32 Cito desde la edición de Francisco López Estrada. Madrid, Clásicos Castalia, 1987.

33 Jonoufn Casaldouero, en «Cervantes rechaza la pastoril y no acepta la picarescaw, Bulletin of Hispanic Studies, 61, 1984, afirma que el autor «al ir a escribir La Galatea (1585) lo que más le urge es romper la forma de la Diana, con su centro tan bien mancado, que nos conduce de la desarmonía a la armonfax (283). El mismo autor en aCervantes: de La Galatea al Persiles», Homenaje a Jose Manuel Blecua. Madrid, Gredos, 1983, 135-40, anade que ya en La Galatea «los personajes cervantinos se mueven atormentados por el impulso de las pasiones, modeladas segun el caracter, de aquí el dramatismo y el accidentado vaiven de sus vidas que impone la forma de marafia en la misma novela» (136). De hecho, el dinamismo 
puede notar que el escritor junta todas las que Montemayor y Gil Polo han empleado en sus respectivas novelas, añade la mayéutica y la irónica, e intensifica el valor de la función catártica. En efecto, en los dos modelos no hay ningún episodio que se pueda comparar al de Lisandro y que implique, por lo tanto, la necesidad de restablecer con el canto una armonía que realmente ha sido perdida para siempre. Además, como hemos visto, en La Galatea Cervantes se sirve de toda la gama de poemas celebrativos, con la única excepción de la égloga piscatoria, pero sin concederle el gran espacio que Gil Polo le otorga en su obra. En cuanto a las funciones narrativas hay que reconocer que nuestro autor utiliza también todos los posibles recursos y que destaca, con respecto a los modelos, por el uso de la suspensión, de la internupción y del contrapunto. Estas modificaciones y añadiduras, que Cervantes introduce en su novela, adquieren una importancia mayor si se consideran dentro de la arquitectura general de la misma que, como sabemos, se caracteriza por la fragmentación, la complejidad y la proliferación de anécdotas, personajes y recursos narrativos. Para corroborar estas observaciones veamos concretamente cómo, por ejemplo, el primer libro de La Galatea se diferencia en el uso poético con respecto a los correspondientes de la Diana y de la Diana enamorada.

La obra de Montemayor se abre con una larga introducción que comprende cinco intervenciones poéticas cuya función es presentar a dos de los protagonistas, Sireno y Sylvano, con sus respectivas cuestiones amorosas. Después de una breve pausa entra en la escena pastoril Selvagia la cual, intercalando algunos poemas a su narración, cuenta su fracasada historia de amor. Las composiciones que ella entona en compaña de los pastores no añaden prácticamente nada a lo que cuenta en prosa y sirven simplemente para cerrar el fragmento narrativo enfatizando sus desventuras amorosas. El libro termina con el canto que los tres pastores entonan para entretenerse durante el camino de vuelta a la aldea. El incipit de la novela de Gil

novelístico y la multiplicidad de recursos bien pueden ser una herencia boccachesca. A este propósito Emmio Alarcos Garcta en su trabajo «Cervantes y Boccaccio», Estudios Cervantinos. Valencia, Mediterráneo, 1950, 197-235, reconoce que «Boccaccio y Cervantes despliegan plenitud de recursos para mantener despierta la atención del lector, consiguiéndolo por un continuo progreso en el relato, por el movimiento y la variedad de incidentes» (215-6). LOPEZ ESTRADA hablando de las obras pastoriles de Boccaccio, el Ameto y el Ninfale Fiesolano, en Los libros de pastores, sefiala que «No basta a Boccaccio narrar la quietud contemplativa de un estado espiritual, como después ocurrirá con la estática Arcadia. (...) En Boccaccio la agilidad narrativa alinea los hechos de la anécdota; los dos personajes, el pastor Árico y la ninfa Ménsola, están movidos por un resorte vital que se distiende y empuja los acontecimientos» (130). 
Polo es parecido al de la otra en cuanto Diana y Alcida entonan sucesivamente unos poemas, propios y ajenos, que alternan quejas y cuestiones amorosas. Con la aparición del esposo de la protagonista, las dos pastoras interrumpen sus pláticas y se mesuran en un canto amebeo de entretenimiento y de ejercicio poético. La siguiente llegada de Marcelio, cantando una canción de amor, provoca la huida de Alcida, su antigua prometida. El nuevo personaje entonces cuenta a Diana la historia de sus desventuras, intercalándola con un soneto y una epístola que completan la narración. Los dos se ponen luego en camino y topan con Tauriso y Berardo, ambos enamorados de Diana, que entonan un canto amebeo quejándose de su amor imposible. Todos juntos siguen cantando para entretenerse hasta llegar a la aldea. Desde esta breve sinopsis resulta evidente que la sencilla estructura tripartita del primer libro de la Diana se complica ligeramente en la obra de Gil Polo por el concurso de más personajes y con el esbozo de un dinamismo en la otra inexistente ${ }^{34}$. Si finalmente pasamos a La Galatea vemos que la estructura del primer libro se compone de cinco segmentos narrativos. La novela se abre con el canto de Elicio que se presenta como el tópico pastor enamorado. Sus versos se interrumpen por la llegada de Erastro y los dos juntos entonan un canto amebeo que sirve para delinear la figura ideal de Galatea. Este cuadro id́lico se quiebra bruscamente por la llegada de Lisandro y Carino corriendo y por el asesinato de este último. Acto seguido, el pastor homicida desahoga su congoja en unos versos que anticipan algunos datos de la historia creando expectativa en su auditorio pastoril. En el tercer apartado narrativo aparece Galatea que, a través de un soneto, no hace sino reiterar la frialdad y la rigidez de su personaje, ya anticipada en el incipit. Luego se intercala otra historia: la de Teolinda que, después de aludir a su desesperación amorosa con una canción, cuenta a Galatea una parte de sus desventuras y entona la sextina que le reveló el amor de Artidoro. Las pastoras son interrumpidas por la aparición de una liebre huyendo de los cazadores y, sucesivamente, por la llegada del desamorado Lenio que canta contra el amor. Empieza luego el último apartado que comprende la apología poética del sentimiento amoroso por parte de Elicio, la casi pelea entre Erastro y Lenio y el soneto de Florisa que comenta dicha contienda.

34 Sin embargo, comenta López Estrada, en la edición citada, a propósito de la arquitectura de la obra: whay que reconocer que Gaspar Gil se atiene a un concepto de maestría "clásica" que está en relación con Sannazaro, y lo acepta en cuanto a una preferencia por la simplicidad argumental. La Diana enamorada, en el ciclo de los libros de pastores, está situada en el grupo de las obras "conservadoras". (...) esto lo entiendo en relación con el ritmo expositivo de la obra en cuanto al curso de los sucesos pastoriles» (27-8). 
Comparando este libro con los dos precedentes salta a la vista la extremada complicación de la estructura y la intensificación de los recursos poéticos, tal como habíamos postulado anteriormente. Mientras que en las obras de Montemayor y Gil Polo el número empleado de funciones poéticas es bastante reducido -abrir y cerrar fragmentos narrativos, introducir personajes y situaciones, expresar sentimientos, teorizar sobre el amor- en La Galatea se potencia la función de anticipar elementos de las historias intercaladas, y se añaden las de crear expectativa y contrapunto, alcanzar un objetivo, defender una opinión, comentar. Además el juego prosa-verso resulta ya de por sí más complicado porque se inserta en una arquitectura sumamente elaborada. Si extendiéramos el estudio a los demás libros, llegaríamos sin duda a los mismos resultados. Pero ha llegado el momento de sacar nuestras conclusiones.

Cuando Cervantes se puso a escribir La Galatea, la novela pastoril ya había alcanzado su apogeo: era una maniera literaria que contaba con numerosos modelos por imitar. Nuestro autor, al volver del cautiverio de Argel, para el mundo de las letras era un perfecto desconocido; diríase que no sabía cómo recortarse un espacio en el hostil ambiente literario que lo rodeaba. Pobre, amargado y sin mecenas que lo protegieran, decidió jugar la carta del género de moda que, con su aparato de poesía laudatoria, le posibilitaba elogiar a los ingenios y políticos contemporáneos. El empleo del género mixto le impuso ciertas limitaciones, pero Cervantes, que ya en su opera prima muestra una clara voluntad de experimentar con el arte narrativo, sigue las reglas con cierta libertad dejando campo libre a su ingenio. Como hemos visto a lo largo de nuestro trabajo, el escritor utiliza todas las posibles funciones poéticas para que la lírica insertada se funda narrativa y estéticamente con la prosa, sirviéndose del juego verso-narración para crear una compleja y fragmentada estructura novelística. Las convenciones pastoriles le permiten también lucir sus calidades de poeta y esbozar algunas situaciones semi-teatrales, conforme a sus grandes pasiones literarias. Muchos de los recursos y de las funciones ya sea narrativas, ya sea poéticas que el escritor utiliza en su novela primeriza, existen ya en los arquetipos del género, como en la Diana de Montemayor y la de Gil Polo. Sin embargo la habilidad cervantina para complicar la arquitectura de la obra y para jugar con todas las posibilidades que el lenguaje le depara le hace superar ampliamente a sus modelos.

Para concluir podemos afirmar, por tanto, que con La Galatea Cervantes ha dado el primer paso fundamental hacia el perfeccionamiento de la técnica narrativa y que, precisamente con la inten- 
sificación de los recursos literarios ya presentes en la tradición, lleva a la disolución la novela pastoril de la cual su trayectoria literaria, tal vez por casualidad o conveniencia, había partido.

Marcella Trambaioli University of Illinois 